\title{
Perinatal programming of obesity: an introduction to the topic
}

\section{Catalina Pico and Andreu Palou*}

Laboratory of Molecular Biology, Nutrition and Biotechnology (Nutrigenomics), CIBER de Fisiopatología de la Obesidad y Nutrición (CIBEROBN), University of the

Balearic Islands (UIB), Palma de Mallorca, Spain

${ }^{*}$ Correspondence: andreu.palou@uib.es

Edited by:

Geoffrey A. Head, BakerIDI Heart and Diabetes Institute, Australia

Reviewed by:

James A. Armitage, Monash University, Australia

Keywords: metabolic programming, maternal nutrition, gestation, lactation, obesity, leptin

A new paradigm for obesity prevention has emerged from the idea that nutritional and other environmental factors in early life have a profound influence on lifelong health. This notion is gaining increasingly great interest since the development of Barker's hypothesis of the "fetal origin of adult diseases" (Barker, 1990). A number of human epidemiology and animal model studies have shown that nutritional conditions during critical stages of development affect susceptibility to chronic diseases in adulthood, including cardiovascular disease, obesity, type II diabetes, and osteoporosis (Ong and Dunger, 2004; Remacle et al., 2004; Novak et al., 2006). Interactions between pre- and postnatal environment have also been described. For instance, accelerated postnatal growth after fetal growth restriction (the so-called "catch-up" growth) has been associated with adverse outcomes in later life (Eriksson et al., 1999; Dulloo et al., 2006).

The "thrifty phenotype hypothesis" (Hales and Barker, 2001) expresses that the rapidly changing incidence of obesity cannot be explained in terms of genetic changes. It proposes that when a fetus grows under conditions of undernutrition, various strategies in the development of organs and metabolic changes will undertake to maximize the chances of postnatal survival under conditions of food shortage; however, these adaptations will be detrimental to health if "adequate" nutrition is received later on (Hales and Barker, 2001). In this regard, the word "programming", first introduced by Lucas (1991), has been adopted to describe the linkages between fetal life and longterm consequences (Gluckman and Hanson, 2004). It involves the notion that a stimulus that operates within a critical or sensitive period of development can lead to lasting or permanent effects on the structure or function of the body (Lucas, 2000).

Gestation and lactation are disclosed as critical periods, and both food restriction and overnutrition can lead to lasting effects in the offspring, thereby changing propensity to obesity and related metabolic alterations in adult life (McMillen and Robinson, 2005; Cottrell and Ozanne, 2008; Sanchez et al., 2012). Adaptive responses occurring in early life to face an adverse environment may result in new physiological set points intended to maximize immediate changes for survival. The "predictive adaptive response" hypothesis proposes that a mismatch between the pre- and postnatal environment is a major determinant of subsequent disease (Gluckman and Hanson, 2004).
Health or disease phenotypes are therefore the consequence of interaction between genetic and nutritional and environmental history, starting from the moment of conception, or even before. Within this context, here we describe, review and discuss known conditions in humans and animal models that have been associated with early programming of obesity, endocrine function and metabolic disorders, the mechanisms underpinning this linkage, and potential strategies and therapeutic targets for reversing it.

As far as contribution of the environment during perinatal life is concerned, maternal prenatal malnutrition has been associated with obesity and other metabolic alterations in the offspring in a large number of experimental and epidemiological observations (Ravelli et al., 1976; Vickers et al., 2000; Palou et al., 2010). The Dutch famine of 1944-1945 represents an emblematic example of later consequences of fetal malnutrition in humans (Ravelli et al., 1976). Studies performed in different animal models have provided direct proof of principle and biological plausibility of nutritional programming (Vickers et al., 2000; Ozanne, 2001; Langley-Evans, 2007; Thompson et al., 2007; Garcia et al., 2010, 2011; Palou et al., 2012). Unlike the fetal period, moderate maternal calorie restriction during lactation in rats exerts protective effects on the risk of obesity in adulthood (Palou et al., 2010, 2011). These aspects in perinatal maternal calorie restriction, and the different outcomes depending on gender and period, type and severity of restriction, as well as potential mechanisms involved in these processes have been reviewed (Pico et al., 2012).

Potential strategies and critical windows of development for reversing adverse effects induced as a consequence of developmental malprogramming have also been addressed (Vickers and Sloboda, 2012). In this regard, the hormone leptin is receiving special attention as a potential programming factor. The sources of leptin during early critical developmental windows include maternal transplacental transfer of leptin, endogenous fetal leptin, and also milk leptin during lactation (Palou and Pico, 2009; Vickers and Sloboda, 2012). Evidence in humans of the potential role of milk-borne maternal leptin during lactation comes from the observation of an indirect correlation between the concentration of leptin in breast milk and body weight increase in infants (Miralles et al., 2006; Doneray et al., 2009; Schuster et al., 2011). Experimentally, a cause-effect relationship of orally-taken leptin during early life in preventing obesity and other metabolic 
alterations in later life was first shown in neonatal rats supplemented with physiological doses of leptin throughout lactation (Pico et al., 2007). Moreover, subcutaneous injection of leptin into neonatal female rats born to undernourished mothers prevented the development of metabolic compromise in adulthood (Vickers et al., 2005). Therefore, leptin may represent an essential nutrient during lactation in protection against obesity and related disorders in later life, and may also be considered a strategy for the reversion of prenatal adaptations resulting from fetal undernutrition (Pico et al., 2011; Vickers and Sloboda, 2012).

The impact of maternal and paternal obesity and/or overnutrition on endocrine pancreatic development in the offspring and underlying mechanisms are also reviewed (O'Dowd and Stocker, 2013). The authors highlight that, in rodents, maintaining dams on a high-fat diet (HFD) for a single week during pregnancy can impair $\beta$-cell development and function in the offspring (Cerf et al., 2007) and that a paternal HFD also programs $\beta$ cell dysfunction ( $\mathrm{Ng}$ et al., 2010); hence the combined impact of both maternal and paternal diet may produce an exacerbated phenotype.

Although little is known concerning the mechanisms involved, a review of several epidemiological and experimental studies endorses the association between maternal nicotine or tobacco exposure during gestation or lactation and the development of obesity and endocrine dysfunction (Lisboa et al., 2012). A

\section{REFERENCES}

Barker, D. J. (1990). The fetal and infant origins of adult disease. BMJ 301:1111. doi: 10.1136/bmj.301.6761.1111

Beck, B., Richy, S., Archer, Z. A., and Mercer, J. G. (2012). Ingestion of carbohydrate-rich supplements during gestation programs insulin and leptin resistance but not body weight gain in adult rat offspring. Front. Physiol. 3:224. doi: 10.3389/fphys.2012.00224

Cerf, M. E., Williams, K., Chapman, C. S., and Louw, J. (2007). Compromised beta-cell development and beta-cell dysfunction in weanling offspring from dams maintained on a highfat diet during gestation. Pancreas 34, 347-353. doi: 10.1097/MPA.0b013e31802ee9ae

Cottrell, E. C., and Ozanne, S. E. (2008). Early life programming of obesity and metabolic disease. Physiol. Behav. 94, 17-28. doi: 10.1016/j.physbeh.2007.11.017

Doneray, H., Orbak, Z., and Yildiz, L. (2009). The relationship between breast milk leptin and neonatal weight gain. Acta Paediatr. 98, 643-647. doi: 10.1111/j.1651-2227.2008.01192.x

Dulloo, A. G., Jacquet, J., Seydoux, J., and Montani, J. P. (2006). The thrifty 'catch-up fat' phenotype: its impact on insulin sensitivity during growth trajectories to obesity and metabolic syndrome. Int. J. Obes. (Lond.) 30(Suppl. 4), S23-S35. doi: 10.1038/sj.ijo.0803516

Eriksson, J. G., Forsen, T., Tuomilehto, J., Winter, P. D., Osmond, C., and Barker, D. J. (1999). Catchup growth in childhood and death from coronary heart disease: longitudinal study. BMJ 318, 427-431. doi: $10.1136 / \mathrm{bmj} .318 .7181 .427$

Garcia, A. P., Palou, M., Priego, T., Sanchez, J., Palou, A., and Pico, C. (2010). Moderate caloric restriction during gestation results in lower arcuate nucleus NPY- and $\alpha \mathrm{MSH}-$ neurons and impairs hypothalamic response to fed/fasting conditions in weaned rats. Diabetes Obes.Metab. 12, 403-413. doi: 10.1111/j.14631326.2009.01174.x

Garcia, A. P., Palou, M., Sanchez, J., Priego, T., Palou, A., and Pico, C. (2011). Moderate caloric restriction during gestation in rats alters adipose tissue sympathetic innervation and later adiposity in offspring. PLOS ONE 6:e17313. doi: 10.1371/journal.pone.0017313

Gluckman, P. D., and Hanson, M. A. (2004). Developmental origins of disease paradigm: a mechanistic and evolutionary perspective. Pediatr. Res. 56, 311-317. doi: 10.1203/01. PDR.0000135998.08025.FB

Hales, C. N., and Barker, D. J. (2001). The thrifty phenotype hypothesis.

smoke-free environment during the lactation period is essential for improving health outcomes and reducing the risk of future diseases.

Two original articles in rodents addressing the effects of maternal intake of an excess of carbohydrates during gestation in the offspring are also included (Beck et al., 2012; Samuelsson et al., 2013). Intake of a sucrose-rich diet by pregnant mice leads to an exacerbation of factors associated with cardiovascular risk in the adult offspring (Samuelsson et al., 2013). In turn, intake of carbohydrate supplements in rats during gestation appears to program insulin and leptin resistance in adult offspring and may predispose to the development of obesity under palatable energy dense diets (Beck et al., 2012). These associations remain to be explored in humans.

\section{ACKNOWLEDGMENTS}

The authors acknowledge funding support from the European Union's Seventh Framework Programme FP7 under grant agreement n. 244995 (BIOCLAIMS Project), the Spanish Government (grant AGL2012-33692), and the Instituto de Salud Carlos III, Centro de Investigación Biomédica en Red Fisiopatología de la Obesidad y Nutrición, CIBERobn. Our Laboratory is a member of the European Research Network of excellence NuGO (The European Nutrigenomics Organization, EU Contract: noFP6506360).

Br. Med. Bull. 60, 5-20. doi: $10.1093 / \mathrm{bmb} / 60.1 .5$

Langley-Evans, S. C. (2007). Metabolic programming in pregnancy: studies in animal models. Genes Nutr. 2, 33-38. doi: 10.1007/s12263-0070005-X

Lisboa, P. C., de Oliveira, E., and de Moura, E. G. (2012). Obesity and endocrine dysfunction programmed by maternal smoking in pregnancy and lactation. Front. Physiol. 3:437. doi: 10.3389/fphys.2012.00437

Lucas, A. (1991). Programming by early nutrition in man. Ciba Found. Symp. 156, 38-50. discussion 50-55. doi: 10.1002/97804 70514047.ch4

Lucas, A. (2000). Programming not metabolic imprinting. Am. J. Clin. Nutr. 71, 602.

McMillen, I. C., and Robinson, J. S. (2005). Developmental origins of the metabolic syndrome: prediction, plasticity, and programming. Physiol. Rev. 85, 571-633. doi: 10.1152/physrev.00053.2003

Miralles, O., Sanchez, J., Palou, A., and Pico, C. (2006). A physiological role of breast milk leptin in body weight control in developing infants. Obesity (Silver Spring) 14, 1371-1377. doi: 10.1038/oby.2006.155

Ng, S. F., Lin, R. C., Laybutt, D. R., Barres, R., Owens, J. A., and
Morris, M. J. (2010). Chronic highfat diet in fathers programs betacell dysfunction in female rat offspring. Nature 467, 963-966. doi: 10.1038/nature09491

Novak, D. A., Desai, M., and Ross, M. G. (2006). Gestational programming of offspring obesity/hypertension. J. Matern. Fetal. Neonatal. Med. 19, 591-599. doi: 10.1080/14767050600708233

O'Dowd, J. F., and Stocker, C. J. (2013). Endocrine pancreatic development: impact of obesity and diet. Front. Physiol. 4:170. doi: 10.3389/fphys.2013.00170

Ong, K. K., and Dunger, D. B. (2004). Birth weight, infant growth and insulin resistance. Eur. J. Endocrinol. 151(Suppl. 3), U131-U139. doi: 10.1530/eje.0.151U131

Ozanne, S. E. (2001). Metabolic programming in animals. $\mathrm{Br}$. Med. Bull. 60, 143-152. doi: $10.1093 / \mathrm{bmb} / 60.1 .143$

Palou, A., and Pico, C. (2009). Leptin intake during lactation prevents obesity and affects food intake and food preferences in later life. Appetite 52, 249-252. doi: 10.1016/j.appet.2008.09.013

Palou, M., Konieczna, J., Torrens, J. M., Sanchez, J., Priego, T., Fernandes, M. L., et al. (2012). Impaired insulin and leptin sensitivity in the offspring of moderate caloricrestricted dams during gestation 
is early programmed. J. Nutr. Biochem. 23, 1627-1639. doi: 10.1016/j.jnutbio.2011.11.005

Palou, M., Priego, T., Sanchez, J., Torrens, J. M., Palou, A., and Pico, C. (2010). Moderate caloric restriction in lactating rats protects offspring against obesity and insulin resistance in later life. Endocrinology 151, 1030-1041. doi: 10.1210/en.2009-0934

Palou, M., Torrens, J. M., Priego, T., Sanchez, J., Palou, A., and Pico, C. (2011). Moderate caloric restriction in lactating rats programs their offspring for a better response to HF diet feeding in a sex-dependent manner. J. Nutr. Biochem. 22, 574-584. doi: 10.1016/j.jnutbio.2010.05.001

Pico, C., Jilkova, Z. M., Kus, V., Palou, A., and Kopecky, J. (2011). Perinatal programming of body weight control by leptin: putative roles of AMP kinase and muscle thermogenesis. Am. J. Clin. Nutr. 94, 1830S-1837S. doi: 10.3945/ajcn.110.000752

Pico, C., Oliver, P., Sanchez, J., Miralles, O., Caimari, A., Priego, T., et al. (2007). The intake of physiological doses of leptin during lactation in rats prevents obesity in later life. Int. J. Obes. (Lond.) 31, 1199-1209. doi: 10.1038/sj.ijo.0803585
Pico, C., Palou, M., Priego, T., Sanchez, J., and Palou, A. (2012). Metabolic programming of obesity by energy restriction during the perinatal period: different outcomes depending on gender and period, type and severity of restriction. Front. Physiol. 3:436. doi: 10.3389/fphys.2012.00436

Ravelli, G. P., Stein, Z. A., and Susser, M. W. (1976). Obesity in young men after famine exposure in utero and early infancy. $N$. Engl. J. Med. 295, 349-353. doi: 10.1056/NEJM197608122950701

Remacle, C., Bieswal, F., and Reusens, B. (2004). Programming of obesity and cardiovascular disease. Int. J. Obes. Relat. Metab. Disord. 28(Suppl. 3), S46-S53. doi: 10.1038/sj.ijo.0802800

Samuelsson, A. M., Matthews, P. A., Jansen, E., Taylor, P. D., and Poston, L. (2013). Sucrose feeding in mouse pregnancy leads to hypertension, and sex-linked obesity and insulin resistance in female offspring. Front. Physiol. 4:14. doi: 10.3389/fphys.2013.00014

Sanchez, J., Priego, T., Garcia, A. P., Llopis, M., Palou, M., Pico, C., et al. (2012). Maternal supplementation with an excess of different fat sources during pregnancy and lactation differentially affects feeding behavior in offspring: putative role of the leptin system. Mol. Nutr. Food Res. 56, 1715-1728. doi: 10.1002/mnfr.201200211

Schuster, S., Hechler, C., Gebauer, C., Kiess, W., and Kratzsch, J. (2011). Leptin in maternal serum and breast milk: association with infants' body weight gain in a longitudinal study over 6 months of lactation. Pediatr. Res. 70, 633-637. doi: 10.1203/PDR.0b013e31823214ea

Thompson, N. M., Norman, A. M., Donkin, S. S., Shankar, R. R., Vickers, M. H., Miles, J. L., et al. (2007). Prenatal and postnatal pathways to obesity: different underlying mechanisms, different metabolic outcomes. Endocrinology 148, 2345-2354. doi: 10.1210/en.2006-1641

Vickers, M. H., Breier, B. H., Cutfield, W. S., Hofman, P. L., and Gluckman, P. D. (2000). Fetal origins of hyperphagia, obesity, and hypertension and postnatal amplification by hypercaloric nutrition. Am. J. Physiol. Endocrinol. Metab. 279, E83-E87.

Vickers, M. H., Gluckman, P. D., Coveny, A. H., Hofman, P. L., Cutfield, W. S., Gertler, A., et al. (2005). Neonatal leptin treatment reverses developmental programming. Endocrinology 146, 4211-4216. doi: 10.1210/en.2005-0581

Vickers, M. H., and Sloboda, D. M. (2012). Strategies for reversing the effects of metabolic disorders induced as a consequence of developmental programming. Front. Physiol. 3:242. doi: 10.3389/fphys.2012.00242

Received: 29 July 2013; accepted: 30 August 2013; published online: 17 September 2013.

Citation: Pico C and Palou A (2013) Perinatal programming of obesity: an introduction to the topic. Front. Physiol. 4:255. doi: 10.3389/fphys.2013.00255

This article was submitted to Integrative Physiology, a section of the journal Frontiers in Physiology.

Copyright (C) 2013 Pico and Palou. This is an open-access article distributed under the terms of the Creative Commons Attribution License (CC BY). The use, distribution or reproduction in other forums is permitted, provided the original author(s) or licensor are credited and that the original publication in this journal is cited, in accordance with accepted academic practice. No use, distribution or reproduction is permitted which does not comply with these terms. 